\title{
VISUALISASI PENELITIAN TENTANG TEMBANG MACAPAT DARI TAHUN 1981 - 2021 : ANALISIS BIBLIOMETRIK
}

\author{
Oka Irmade $^{\mathrm{a}, 1, *}$, Winarto ${ }^{\mathrm{b}, 2}$ \\ ${ }^{\mathrm{ab}}$ Universitas Slamet Riyadi \\ ${ }^{1}$ irmadeoka@gmail.com, ${ }^{2}$ winbarog19@gmail.com
}

Received 7 June 2021; accepted 2 July 2021; published 30 July 2021

\section{ABSTRACT}

The macapat song in Indonesia has been widely studied and has become an interesting topic for international analysis. The purpose of this study is to provide an overview of the extent to which the tembang macapat has been researched and published in reputable international journals. This study analyzes the literature from 1981 to 2021, identifies the publications each year, the number of articles and their authors, the most researched topics, and how interested they are in those topics. The data came from the Scopus database which was analyzed by the bibliometric method. The results of this study found articles about tembang macapat were published in Scopus indexed journals and topics related to macapat, namely ketoprak, cross-cultural perspectives, social change perspectives, Javanese, writing, and a few others. From the results of this visualization, it is necessary to increase the publication of research results in the international arena so that everything contained in the macapat song can also be known not only in Indonesia.

\section{KEYWORDS}

visualization, tembang macapat, scopus, and bibliometrics.
This is an open access article under the CC-BY-SA license

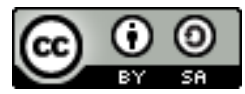

\section{Pengantar}

Tembang macapat merupakan sebuah topik bahasan yang menarik untuk dikaji dari berbagai aspek. Menurut KBBI tembang macapat adalah sebuah puisi Jawa tradisional dimana setiap baitnya mempunyai baris kalimat/gatra tertentu. Setiap gatra mempunyai jumlah suku kata/guru wilangan tertentu, dan berakhir pada bunyi sajak akhir dari guru lagu/guru suara tertentu.

Moh. Hafid Efendi menjelaskan bahwa tembang macapat adalah puisi tradisional dari tanah jawa yang memiliki aturan dalam jumlah baris pada setiap bait, jumlah suku kata dalam setiap baris, juga pada bunyi sajak akhir dalam setiap barisnya. Macapat bisa ditemukan dalam kebudayaan Sunda, Bali, Lombok dan Madura. Leluhur Madura telah mengadopsi dan menjadikannya sebagai khasanah kebudayaan Madura yang memngandung nilai-nilai luhur dan pesan moral yang patut diteladani (Khoiriyah \& Syarif, 2019).

Berbagai penelitian tentang tembang macapat telah banyak dilakukan di Indonesia seperti pengembangan media pembelajaran tembang macapat (Arisyanto, Prasetyo, Untari, \& Sundari, 2021), tembang macapat sebagai penunjang pendidikan karakter (Anto \& Anita, 2019; Winarto, Sarafuddin, \& Devika, 2021), Implementasi HOTS dalam Pembelajaran Tembang Macapat (Alfiah, Sulanjari, \& Setyawati, 2020), Nilai (Wangsa, Suyanto, \& Sulistyo, 2019) Religius pada Kearifan Lokal Tembang Macapat Madura (Effendy, 2021), kritik sosial (Iriyanto, 2020), karawitan (Pamuji, Nugroho, \& Supriyadi, 2020) dan beberapa kajian lainya. Namun topik tembang macapat di kanca internasional perlu juga diketahui sejauhmana telah diteliti dan di publish dalam jurnal internasional bereputasi.

Perkembangan teknologi informasi dapat membantu memetakan juga memvisualisasikan berbagai topik penelitian yang sudah dilakukan melalui analisis statistik dengan berbagai sofware. 
VOSviewer adalah salah satu media dapat digunakan untuk membuat peta penulis atau untuk melihat peta kata kunci berdasarkan data kejadian bersama.

Program VOSviewer dapat menghasilkan peta bibliometrik secara detail, menampilkan peta dengan berbagai sudut pandang, dan menekankan aspek peta yang berbeda (Jan \& Ludo, 2010). Analisis yang dilakukan termasuk seperti mengidentifikasi grup penelitian dan penulis, kutipan artikel yang diterbitkan, konsumsi informasi, faktor dampak, h-indeks, dan di antaralainnya (Romero, Hoz, \& Gonzalez, 2019). Ditambah juga dengan distribusi melalui peta geografi (Irmade, Suwarno, \& Anisa, 2021).

\section{Metode dan Sumber Data}

Jenis penelitian ini termasuk kedalam penelitian deskriptif yang menyajikan gambaran data tentang penelitian tembang macapat. Sumber data diambil dari database SCOPUS yang digali dengan format RIS. Database SCOPUS dipilih karena termasuk pengindeks yang dipercaya dan berpengaruh besar terhadap perkembangan keilmuan. Proses pengumpulan data menggunakan penerapan kata kunci pencarian : TITLE-ABS-KEY (macapat) pada Website Scopus, dengan memasukkan semua tipe dokumen, tidak dibatasi rentan waktunya, tidak dibatasi nama negara sehingga didapatkan 10 dokumen. Metadatanya diambil pada Jumat 4 Juni 2021. Hasil penggalian data yang berbentuk RIS kemudian dianalisis dan digambarkan dengan menggunakan aplikasi VOSviewer.

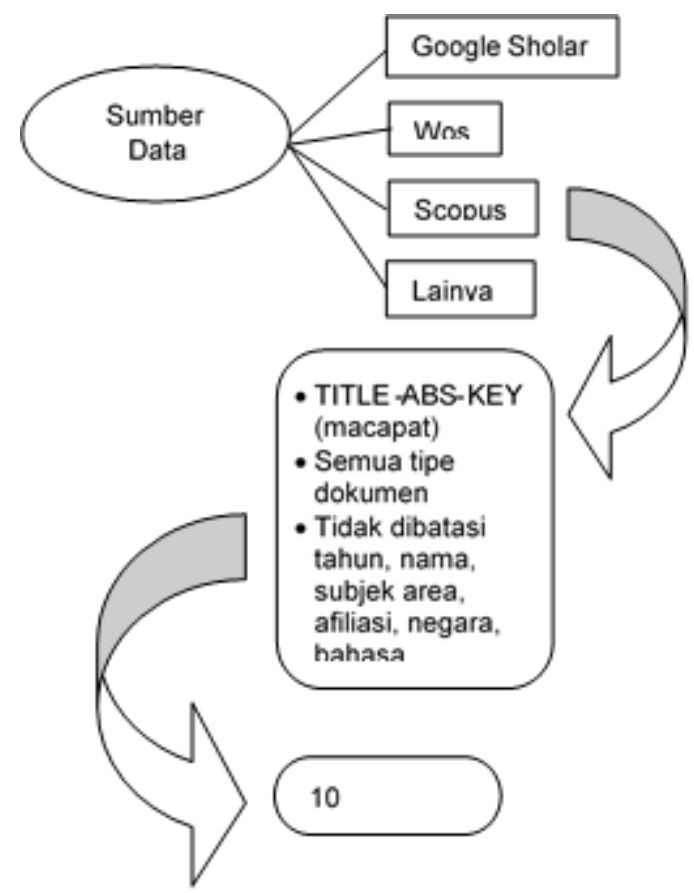

Gambar 1. Tahapan penggalian data

\section{Pembahasan}

\subsection{Dokumen Berdasarkan Tahun}

Jumlah dokumen dengan topik tembang macapat yang dipublis di jurnal terindeks scopus berawal dari tahun 1981 sampai 2021 bulan juni berjumlah 10 dokumen. 


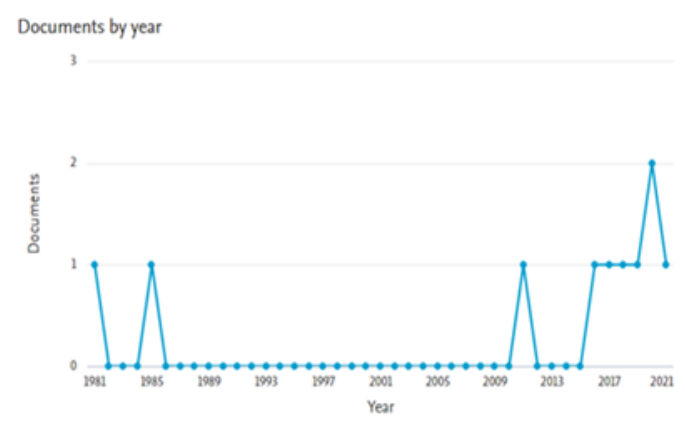

Gambar 2. Jumlah dokumen per tahun (sumber: Scopus)

Dari gambar 1 kita dapat mengetahui grafik yang fluktuatif. Topik tembang macapat pertama kali dipublis di jurnal scopus pada tahun 1981 dengan jumlah 1 dokumen, kemudian 4 tahun kemudian di 1985 terbit 1 dokumen, setelah itu vakum beberapa tahun sampai 2011 terbit lagi 1 dokumen, dilanjut 2016 sampai 2019 menghasilkan 4 dokumen, pada 2020 terbit 2 dokumen dan 2021 baru 1 dokumen.

\subsection{Dokumen Berdasarkan Negara}

Jika melihat asal tembang macapat dari tanah jawa, maka jelas seharusnya negara Indonesialah yang paling banyak meneliti dan mempublikasikanya.

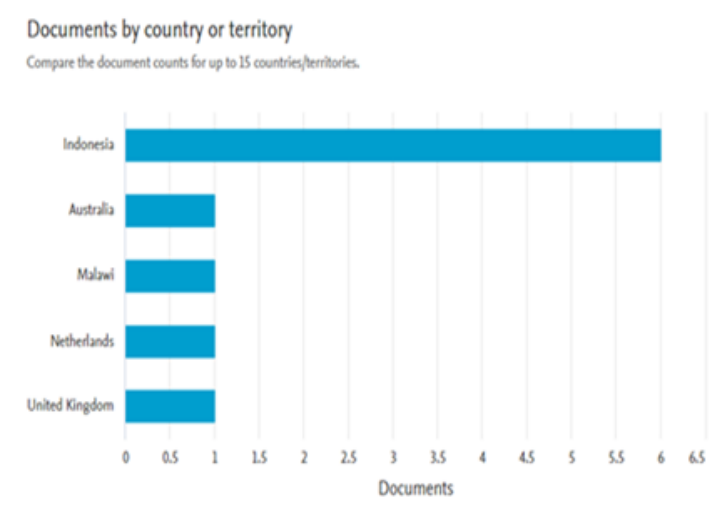

Gambar 3. Jumlah dokumen berdasar negara

(sumber: Scopus)

Dari gambar 2 kita bisa melihat negara Indonesia adalah negara dengan jumlah dokumen yang terbanyak dengan 6 dokumen. Hal ini jelas dikarenakan Indonesia adalah tempat asal budaya dimana tembang macapat muncul. Namun yang unik adalah ada 4 negara dengan masing-masing 1 dokumen seperti Australia, Malawi, Belanda, dan US yang meneliti tentang tembang macapat juga menerbitkanya ke dalam jurnal scopus. Beberapa negara tersebut mungkin ada ketertarikan terhadap budaya Indonesia sehingga fokus mempelajari, meneliti, kemudian mempublikasikanya sebagai bentuk kontribusinya mengenalkan budaya Indonesia.

\subsection{Dokumen Berdasarkan Afiliasinya}

Tidak hanya berdasar kacamata negara saja, kita perlu juga melihat lebih kedalam dari universitas mana saja publikasi tersebut berasal. 
Table 1. Jumlah dokumen berdasar afiliasi

\begin{tabular}{|l|l|c|}
\hline No & \multicolumn{1}{|c|}{ Afilliasi } & Jumlah \\
\hline 1 & Universitas Kebangsaan & 1 \\
\hline 2 & $\begin{array}{l}\text { Institute Seni Budaya } \\
\text { Indonesia }\end{array}$ & 1 \\
\hline 3 & $\begin{array}{l}\text { The Australian National } \\
\text { University }\end{array}$ & 1 \\
\hline 4 & Leiden University & 1 \\
\hline 5 & Durham University & 1 \\
\hline 6 & Universitas Indonesia & 1 \\
\hline 7 & Universitas Jember & 1 \\
\hline 8 & University of Malawi & 1 \\
\hline 9 & $\begin{array}{l}\text { Universitas Negeri } \\
\text { Yogyakarta }\end{array}$ & 1 \\
\hline 10 & $\begin{array}{l}\text { Universitas Negeri } \\
\text { Semarang }\end{array}$ & 1 \\
\hline
\end{tabular}

Tabel 1 dapat memberikan informasi berbagai universitas didunia yang memberikan kontribusi meskipun baru 1 dokumen disetiap universitas.

\subsection{Dokumen Berdasarkan Area}

Topik tembang macapat bisa dilihat dari berbagai perspektif termasuk dari berbagai disiplin ilmu.

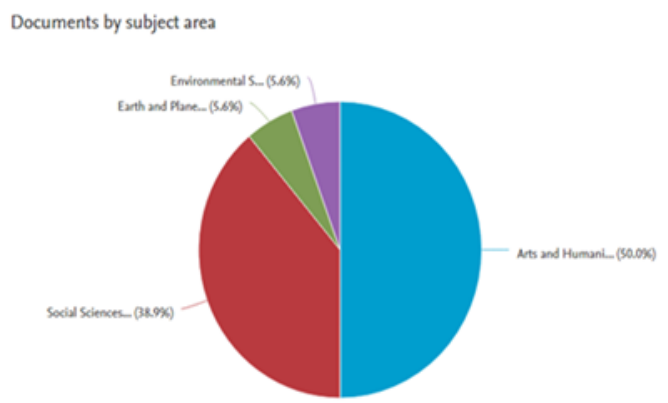

Gambar 4. Jumlah dokumen berdasar area (sumber: Scopus)

Dari gambar 3 didapatkan informasi bahwa kajian tentang tembang macapat terbanyak masuk dalam penggolongan disiplin ilmu Seni dan Manusia sebesar 50\%, kemudian disusul disiplin ilmu lain seperti : ilmu sosial, ilmu lingkungan dan lainya. Hal ini menandakan belum banyak kajian dari disiplin ilmu lain yang mengkaji tentang tembang macapat, meskipun sudah ada satu contoh kajian macapat dalam prespektif agama (Cahyono, Widodo, Jazuli, \& Murtiyoso, 2020).

\subsection{Dokumen Berdasarkan Penulis}

Penulis dari berbagai negara telah berkontribusi dengan ketertarikanya terhadap topik tembang macapat meskipun baru sebatas 1 dokumen disetiap orangnya. Berdasarkan data scopus penulis tersebut adalah : Bogaerts, E.; Cahyono, A.; Elmunsyah, H.; Hum, N.M.; Hum, S.M.; Indriyanti, V.L.; Jazuli, M.; Juanda, J.; Kurnain, J.; Kusumawardhani, W.; McDonald, B.; Murtiyoso, O.; 
Posnett, D.; Ristanti, P.Y.; Setiawan, W.; Soraya, D.U.; Sundari, A.; Van Zanten, W.; Wibowo, A.; Widodo, W.

\subsection{Pemetaan Topik Tembang Macapat}

Melalui analisis berbantuan software VOSviewer terlihat visualisasi topik-topik yang saling terkait dengan tembang macapat di jurnal scopus. Topik-topik yang belum terkait atau yang belum ada bisa dijadikan bahan kajian untuk diteliti sehingga kemungkinan dapat diterima pada jurnal scopus dan menjadi kebaruan dalam penelitian atau novelty.

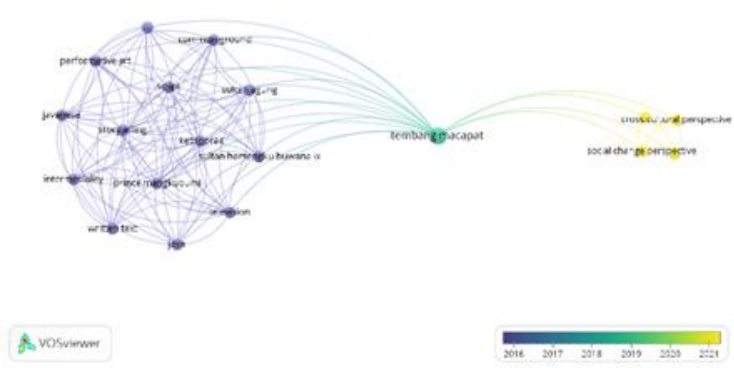

Gambar 5. Overlay Visualization

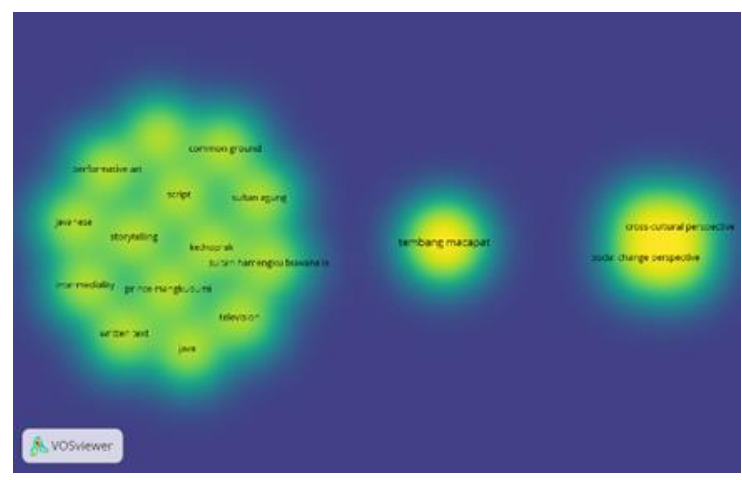

Gambar 6. Density Visualization

\section{7. Kajian Dokumen Macapat di Scopus}

Berdasarkan hasil penggalian data tentang macapat, ada 10 dokumen yang terbit di jurnal scopus yang mengkaji dan membahas berbagai subjek. Pembahasan setiap dokumen terdiri sebagai berikut:

\subsubsection{Self-Introspection in the Search of Identity in Serat Jayengbaya by Ranggawarsita.} (Kusumawardhani, 2018)

Penelitian ini mencoba mengkaji struktur naratif teks untuk menentukan tema tekstual Serat Jayengbaya yang kemudian dilengkapi dengan konsep introspeksi yang diajarkan oleh Ki Ageng Suryomentaram. Penelitian ini menerapkan teori struktural yang ditulis oleh Burhan Nurgiyantoro. Dari struktur naratif, ditemukan bahwa tema Serat Jayengbaya adalah sebuah perjalanan untuk menemukan jati diri seseorang.

\subsubsection{The Discourse on Islam and Music in West Java, with Emphasis on the Music Group, Ath-} Thawaf (Van Zanten,2011).

Mengeksplorasi perdebatan umum tentang musik dan Islam di Indonesia dan yang beredar di Jawa Barat, dan kemudian berfokus pada studi kasus topik seputar band kontemporer, Ath-Thawaf. 
mengungkapkan bagaimana bentuk syair khusus, seperti macapat, dibubuhkan pada berbagai acara ritual dan digunakan untuk menyebarkan ajaran Islam ke seluruh wilayah Jawa Barat.

\subsubsection{Bawa sekar macapat dhandhanggula padhasih: An introduction to one example of javanese vocal music (Posnett, 2007).}

Memberikan gambaran dan pemahaman mendalam tentang salah satu contoh musik jawa yaitu Bawasekar macapat dhandhang gula padhasih.

\subsubsection{Revisiting classical literary texts in the tembang macapat: Strong locality values as social control (Sundari, 2021).}

Penelitian ini mengeksplorasi teks Tembang Macapat yang terdiri dari Tembang Sinom dan Tembang Pangkur. Hasil analisis ini mengungkapkan nilai-nilai moral dilihat melalui tiga perspektif, yaitu perspektif lintas budaya, perspektif sosial, dan perspektif perubahan sosial. Implikasinya, bagaimana ketiga perspektif tersebut melihat nilai-nilai moral yang terkandung dalam Tembang Macapat sehingga membantu mengatasi masalah radikalisme dan korupsi

\subsubsection{The song of macapat semarangan: The acculturation of javanese and islamic culture (Cahyono et al., 2020).}

Penelitian ini menjelaskan tembang macapat Semarangan yang merupakan hasil akulturasi budaya Jawa dan Islam. Macapat Semarangan memiliki karakteristik aransemen yang unik, alur lagu panjang dan menggunakan ornamen musik yang rumit dengan ketinggian nada yang bervariasi. Bentuk manifestasi dari hasil akulturasi budaya Jawa dan Islam dilihat dari susunannya di bagian Adzan (panggilan untuk sholat) dan tilawatil Alquran. Adzan menggunakan tangga nada diatonis, beberapa macapat Semarangan

\subsubsection{History of inheritance of Wayang Topeng Malangan (Malang traditional mask puppet) in}

Pakisaji and Tumpang (Wibowo, Kurnain, \& Juanda, 2020).

Menjelaskan sejarah dan proses pewarisan seni wayang topeng di dua perwakilan pertapaan (padepokan) di Malang yaitu Padepokan Asmoro Bangun di kecamatan pakisaji dan Mangun Dharma di Kecamatan Tumpang.

\subsubsection{Development of a mobile based education game on Parikan, Paribasan, and Tembang as a} java language learning media for vocational students (Soraya, Elmunsyah, Indriyanti, \& Setiawan, 2019).

Pengembangan Game Edukasi berbasis mobile untuk Parikan, Paribasan, dan Tembang sebagai media pembelajaran Bahasa Jawa untuk siswa SMK. Hasil penelitian menunjukkan bahwa game ini valid dan layak untuk digunakan, $87 \%$ dari siswa memberikan tanggapan yang sangat menarik dan $13 \%$ siswa memberikan tanggapan yang menarik.

\subsubsection{Development of learning media macapat with solfegio technique in android applications}

(Hum, S.M.\& Hum, N.M.,2017).

Pengembangkan media pembelajaran tembang macapat dengan teknik solfegio dalam aplikasi android untuk siswa SMP dan SMA di Yogyakarta.

\subsubsection{The installation of Prince Mangkubumi: Performing Javanese history (Bogaerts, 2016).}

Memberikan gambaran yang berfokus pada kisah kenaikan takhta Pangeran Mangkubumi, bagaimana versi kethoprak di televisi menggabungkan teks (tertulis) dengan pertunjukan (aural/visual) yang dimediasi untuk menyajikan cerita.

\subsubsection{The Serat Rama of Yasadipura: Some Structural Determinants in Tembang Macapat} (Mcdonald \& Mcdonald, 2007).

Memberikan gambaran mengenai kajian tentang struktur dari tembang macapat terkhusus yaitu Serat Rama Yasadipura. 


\section{Kesimpulan}

Hasil penelitian tentang tembang macapat di Indonesia sudah banyak dikaji namun masih terbatas publikasinya di jurnal nasional. Masih dikategorikan sedikit publikasi yang sampai menembus jurnal internasional bereputasi. Meski begitu lima tahun terakhir menandakan peningkatan jumlah dokumen, dan ketertarikan berbagai negara dalam penelitian topik terkait. Dengan melihat gambaran/visualisasi ini diharapkan peneliti yang akan datang bisa memilih dan memilah topik-topik mana saja yang belum dikaji sehingga dimungkinkan dapat menjadi kajian baru dan bisa terbit di jurnal internasional bereputasi sehingga lebih mengenalkan tembang macapat ke kancah internasional.

\section{Kepustakaan}

Alfiah, Sulanjari, B., \& Setyawati, N. (2020). Implementasi HOTS dalam Pembelajaran Tembang Macapat di SMK Kota Semarang. JISABDA, 2(1), 35-42.

Anto, P., \& Anita, T. (2019). TEMBANG MACAPAT SEBAGAI PENUNJANG PENDIDIKAN KARAKTER. DEIKSIS, 11(01), 77-85. https://doi.org/10.30998/deiksis.v11i01.3221

Arisyanto, P., Prasetyo, S. A., Untari, M. F. A., \& Sundari, R. S. (2021). Pengembangan Media Pembelajaran Tembang Macapat Berbasis Android Bagi Mahasiswa PGSD UPGRIS. BASICEDU, 5(3), 1584-1592. https://doi.org/https://doi.org/10.31004/basicedu.v5i3.945

Bogaerts, E. (2016). The installation of Prince Mangkubumi. Wacana, 17(3), 473-505. https://doi.org/10.17510/wacana.v17i3.456

Cahyono, A., Widodo, W., Jazuli, M., \& Murtiyoso, O. (2020). The Song of Macapat Semarangan : The Acculturation of Javanese and Islamic Culture. Harmonia, 20(1), 10-18. https://doi.org/http://dx.doi.org/10.15294/harmonia.v20i1.25050something

Effendy, M. H. (2021). Nilai Religius pada Kearifan Lokal Tembang Macapat Madura. Khazanah Theologia, 3(1), 1-12. https://doi.org/10.15575/kt.v3i1.10959

Hum S.M.\&,Hum N.M.(2017). Development of learning media macapat with solfegio technique in android applications. Man in India, 97(24), 291-303.

Iriyanto, E. (2020). Tembang Macapat: Kritik Sosial Sedulur Sikep terhadap Ekspansi Industri Semen di Pegunungan Kendeng. Sutasoma: Jurnal Sastra Jawa, 8(2), 70-79.

Irmade, O., Suwarno, \& Anisa, N. (2021). Research Trends of Serious Games : Bibliometric Analysis. Journal of Physics: Conference Series, 1842. https://doi.org/10.1088/1742-6596/1842/1/012036

Jan, N., \& Ludo, V. E. (2010). Software survey : VOSviewer , a computer program for bibliometric mapping, 523-538. https://doi.org/10.1007/s11192-009-0146-3

Khoiriyah, F., \& Syarif, Z. (2019). Eksistensi Tembang Mamaca ( Macapat) Dalam Dimensi Kultur, Mistik Dan Religius; Studi Etnografi di Desa Serabi Barat Modung Bangkalan. Tribakti, 30(5), 324-334. https://doi.org/https://doi.org/10.33367/tribakti.v30i2.819

Kusumawardhani, W. (2018). Self-Introspection in the Search of Identity in Serat Jayengbaya by Ranggawarsita. In IOP Conference Series: Earth and Environmental Science (p. 175). IOP. https://doi.org/10.1088/1755-1315/175/1/012114

Mcdonald, B., \& Mcdonald, B. (2007). The Serat Rama of Yasadipura : Some structural determinants in Tembang Macapat. Indonesia Circle. School of Oriental \& African Studies. Newsletter, 9(26), 37-41. https://doi.org/10.1080/03062848108723841

Pamuji, I. A., Nugroho, S., \& Supriyadi, S. (2020). The Rule of Macapat Songs in Karawitan. In Advances in Social Science, Education and Humanities Research (Vol. 421, pp. 42-47).

Posnett, D. (2007). Bawa sekar macapat dhandhanggula padhasih: An introduction to one example of javanese vocal music. Indonesia Circle. School of Oriental \& African Studies. Newsletter, (March 2015), 37-41. https://doi.org/10.1080/03062848508729611

Romero, A., Hoz, J. D. La, \& Gonzalez, J. D. (2019). Robots in nursing education : a bibliometric analysis. Journal of Physics : Conference Series, 1391. https://doi.org/10.1088/1742-6596/1391/1/012129 
Gelar: Jurnal Seni Budaya

Vol 19, No 1 (2021)

ISSN 1410-9700 (print) | 2655-9153 (online)

https://jurnal.isi-ska.ac.id/index.php/gelar

Soraya, D. U., Elmunsyah, H., Indriyanti, V. L., \& Setiawan, W. (2019). Development of a Mobile Based Education Game on Parikan, Paribasan, and Tembang As a Java Language Learning Media For Vocational Students. International Journal of Innovation, Creativity and Change, 8(1), 65-79.

Sundari, A. (2021). Revisiting classical literary texts in the tembang macapat: Strong locality values as social control. International Journal of Literary Humanities, 19(1), 61-73.

Van Zanten, W. (2011). The Discourse on Islam and Music in West Java, with Emphasis on the Music Group, Ath-Thawaf. Divine Inspirations: Music and Islam in Indonesias

Wangsa, B. S., Suyanto, \& Sulistyo, E. T. (2019). A Study on Noble Values of Tembang Macapat Kinanthi in Serat Wulangreh by Pakubuwono IV. In Advances in Social Science, Education and Humanities Research (ASSEHR) (Vol. 279, pp. 170-174).

Wibowo, A., Kurnain, J., \& Juanda, J. (2020). History of Inheritance of Wayang Topeng Malangan ( Malang Traditional Mask Puppet ) in Pakisaji and Tumpang. Harmonia: Journal of Arts Research and Education, 20(1), 73-83. https://doi.org/http://dx.doi.org/10.15294/harmonia.v20i1.24785

Winarto, Sarafuddin, \& Devika, B. D. (2021). OPTIMALISASI PERAN GURU DALAM MENDIDIK KARAKTER SISWA MELALUI MEDIA TEMBANG MACAPAT PANGKUR PUPUH 3SERAT WEDHATAMA. Adi Widya, 5(1). https://doi.org/10.33061 